\title{
Opinión pública y cambio electoral en España. Claves ante el reto europeo y la crisis política y económica
}

\author{
Mariano Torcal Llorente (editor) \\ Centro de Investigaciones Sociológicas, 2018, 246 páginas
}

Melina Johanna Levy

En los últimos años ha tenido lugar un fenómeno de colosal importancia en España. El cambio cualitativo y cuantitativo del sistema de partidos, anteriormente estable y bipartidista, devino en un sistema fragmentado con nuevos competidores de peso. Este fenómeno ha sido explicado en función de las consecuencias de la crisis económica y posteriores medidas de austeridad. Sin embargo, como se aprecia en el primer capítulo de este libro, Mariano Torcal propone una hipótesis diferente, que será corroborada con una metodología inédita, basada en un estudio de panel online realizado con seis olas aplicadas al mismo grupo durante un plazo de dos años: CIUPANEL.

En el segundo capítulo Mariano Torcal y Pablo Christmann muestran que el deterioro de la confianza en las instituciones españolas ha afectado la confianza en las instituciones de la Unión Europea, en un contexto de gobierno multinivel. Sin embargo, observan que mientras mayor es el conocimiento de los asuntos que se tratan en la Unión Europea que presentan los ciudadanos, más se incrementa su confianza en dicha institución regional.

En el tercer capítulo Wiebke Weber e Irina Ciornei concluyen que las variables actitudinales y cognitivas tienen tanto poder explicativo de la percepción ciudadana sobre la Unión Europea, como las clásicas variables socioeconómicas y de posicionamiento ideológico. En el caso español en particular, la identificación con una comunidad política y la confianza y conocimiento de las instituciones de la Unión Europea, revisten gran relevancia.

En el cuarto capítulo Javier Lorente, Gema García-Albacete e Irene Martin sostienen que los jóvenes manifiestan una mayor distancia respecto de los partidos tradicionales, en comparación con los adultos. Asimismo, observan que la identificación partidaria no es una variable con capacidad explicativa del voto de los jóvenes, quienes destacan justamente por su escasa experiencia política y por lo tanto, poco desarrollo de la identificación partidaria. Sin embargo, si bien desconfían de las instituciones políticas, ello no se tradujo en abstención electoral, sino en un voto por Podemos, razón por la cual los autores lo consideran un voto protesta.

En el quinto capítulo Lluis Orriols y Sandra León concluyen que tanto la identidad partidaria como el sentimiento nacional, tienen fuerte ascendencia a la hora de sesgar la atribución de responsabilidades. Quien se siente más español que europeo, tiende a culpar a la Unión Europea respecto de los fracasos vinculados a las políticas implementadas. Igualmente, quienes se encuentran identificados con el color político del partido en el gobierno español, tienden a exonerar al gobierno nacional, culpando a la UE por las crisis que atraviesa el país. 
En el sexto capítulo Mariano Torcal, Sergio Martini y Lluís Orriols destacan que tanto la ideología en términos de posicionamiento izquierda-derecha como la identidad partidaria mejoran la competencia electoral. Ambos atajos informativos, promueven la congruencia entre la posición política de los electores y los elegidos. No obstante, a diferencia de lo destacado en investigaciones previas, la identidad partidaria resulta ser un atajo informativo más efectivo que la ideología. Esto se debe a que, las etiquetas ideológicas son más abstractas y ambiguas que las siglas de los partidos.

En el séptimo capítulo José RealDato expone que el voto a Podemos no está relacionado con el euroescepticismo creciente de los años previos a las elecciones del 2014. Tal es así, que la posibilidad de votar por Podemos creció entre aquellos que mejor valoración tenían del proceso de integración europea y entre los mejor informados al respecto. Asimismo, se desmitificó la idea de que la desafección política habría sido responsable de gran parte del voto por Podemos, en tanto, los ciudadanos más alejados de las posiciones reales de los candidatos, tendieron a votar por otros espacios. Posiblemente, la ruptura entre electores y elegidos no esté fundada en un descuerdo entre las posiciones políticas reales, sino en la incapacidad de los candidatos, de comunicar con claridad su posición política.

En el capítulo octavo Guillermo Cordero y Pablo Christmann analizan al votante medio de Podemos. Este votante se caracteriza por realizar un uso intensivo de Internet a la hora de informarse sobre asuntos políticos, y presentar una mayor desconfianza en las instituciones democráticas. Es por esta razón que, se considera que el voto a Podemos es un voto desafecto, aun cuando en las elecciones del 2015 comenzaron a cobrar relevancia nuevamente el posicionamiento ideológico y la identidad nacional, relativamente ausentes en las elecciones a los parlamentarios europeos del 2014. La clave del éxito de Podemos en las elecciones de 2014 fue la canalización del descontento político generalizado. Empero, en las elecciones del 2015, sus votantes han manifestado un reposicionamiento en la escala ideológica y cierta reconfiguración de la identidad regional.

En el capítulo noveno Mariano Torcal y Danilo Serani demuestran que la alienación electoral solo propicia el voto por partidos nuevos en caso de existir un mínimo nivel de confianza en las instituciones políticas. De esta manera, se demuestra que el voto por Podemos no es el voto de quienes desconfían completamente en el sistema político.

Finalmente, Mariano Torcal concluye que el mayor aporte del libro esta vinculado con la búsqueda y fundamentación teórica y estadística de nuevos mecanismos que posibiliten el análisis de la aparición de nuevos partidos en la política española, diferente del tradicional economicismo e instrumentalismo. De esa forma, adquieren preeminencia, tanto, la agencia política que se activa en un contexto de crisis económica profunda como la crisis de representación que de la agencia política se desprende. En otras palabras, la crisis económica del 2008 y las medidas de austeridad posteriormente aplicadas, han sido la prueba de fuego que el sistema de partidos bipartidista tradicional no ha logrado sortear, en la medida en que ni el partido en gobierno a la hora de desatarse la crisis - el Partido Socialista Obrero Espa- 
Revista SAAP $\cdot$ Vol. 13, № 2

ñol— ni el partido que lo reemplazó y dadanas. Por esta razón, el autor concluaplicó las medidas de austeridad —el ye que los nuevos partidos deberán proPartido Popular - lograron responder bar que son verdaderas alternativas reseficientemente ante las demandas ciu- pecto de dichos espacios políticos. 